ASD TECHNICAL REPORT 61-158

\title{
PERCHLORATE ESTER: PREPARATION AND POLYMERIZATION
}

\author{
J. RADELL \\ DIRECTORATE OF MATERIALS \& PROCESSES \\ J. W. CONNOLLY \\ AERONAUTICAL RESEARCH LABORATORY
}

SEPTEMBER 1961

PROJECT No. 7360

AERONAUTICAL SYSTEMS DIVISION

AIR FORCE SYSTEMS COMMAND

UNITED STATES AIR FORCE

WRIGHT-PATTERSON AIR FORCE BASE, OHIO

500 - December 1961 - 15-588 \& 589 